\title{
Stage IIIA Breast Cancer AJCC v7
}

National Cancer Institute

\section{Source}

National Cancer Institute. Stage IIIA Breast Cancer A/CC v7. NCI Thesaurus. Code C7770.

Stage IIIA includes: (TO, N2, M0); (T1, N2, M0); (T2, N2, M0); (T3, N1, M0); (T3, N2, M0). T0: No evidence of primary tumor. T1: T umor $20 \mathrm{~mm}$ or less in greatest dimension. T1 includes T1 mi. T1 mi: Tumor $1 \mathrm{~mm}$ or less in greatest dimension. T2: Tumor more than $20 \mathrm{~mm}$ but not more than $50 \mathrm{~mm}$ in greatest dimension. T3: Tumor more than $50 \mathrm{~mm}$ in greatest dimension. N1: Metastasis to movable ipsilateral level I, II axillary lymph node(s). N2: Metastases in ipsilateral level I, II axillary lymph nodes that are clinically fixed or matted; or in clinically detected ipsilateral internal mammary nodes in the absence of clinically evident axillary lymph node metastases. M0: No clinical or radiog raphic evidence of distant metastasis. M0 includes MO(i+). (AJCC 7th Ed.) 